\title{
Relation between perceived driving disability and scores of vision screening tests
}

\author{
L J van Rijn, H Wilhelm, M Emesz, R Kaper, S Heine, S Nitsch, G Grabner, \\ H J Völker-Dieben
}

Br J Ophthalmol 2002;86:1262-1264

Aim: To determine the relation between perceived driving disability and vision screening tests.

Methods: 93 subjects, aged 50 years and over, with binocular visual acuity of at least 20/80. Perceived driving disability (PDD) was assessed by a questionnaire. Subtracting daytime from night-time driving question scores revealed PDD at night (PDDN), subtracting scores of questions for driving in familiar places from those in unfamiliar places revealed PDD at unfamiliar places (PDDU). Results: PDD was strongly related to visual acuity, contrast sensitivity and useful field of view (UFOV). Specific relations existed between PDDN and Nyktotests and Mesotests and between PDDU and UFOV. These associations were enhanced in a subset of subjects with better visual acuities.

Conclusions: Vision screening tests correlate well with perceived driving disabilities, especially when a subtraction method is used in the questionnaire to reveal condition dependent disabilities. Additional tests for visual acuity are useful, especially in subjects with better visual acuity.

$\mathrm{V}$ ision is beyond doubt the most important source of information for a driver. However, the opinion of the driver about his or her vision has rarely been considered. Any visual impairment that is recognised may lead to adaptation of driving behaviour, such as reduction of speed and avoidance of night-time driving. Moreover, when driving licence selection procedures are based on tests that closely relate to the difficulties experienced in driving, a driving licence refusal may be acceptable.

Over the past years, several questionnaires have been developed for the assessment of vision related quality of life. Most popular is the National Eye Institute-Visual Function Questionnaire. ${ }^{1}$ It has been evaluated in various studies, ${ }^{2-5}$ none of which pay specific attention to driving disabilities.

\section{METHODS}

A total of 93 subjects were selected from patients and visitors to the outpatient departments of the three participating clinics. Subjects were aged 50 years and over and had a presenting visual acuity of 20/80 or more, measured binocularly. Ninety one of 93 subjects were active drivers, two had recently stopped driving.

\section{Perceived driving disability}

Before testing, subjects filled in a questionnaire about perceived disabilities when driving under various conditions (see appendix). Additional questions were about general health $(\mathrm{GH})$, general vision $(\mathrm{GV})$, near vision $(\mathrm{NV})$, and distance vision (DV), most which were selected from the NEIVFQ-25, and about driving frequency and dependency. All questions were scored on a linear $0-100 \%$ scale.

\section{Vision screening tests}

Visual acuity (VA) was measured with the ETDRS chart (logMAR scale), ${ }^{67}$ contrast sensitivity (CS) with the Pelli-Robson chart (log (percentage contrast)), ${ }^{8-10}$ and visual field with the Humphrey field analyser, 120 points two zone screening programme (Humphrey Systems, Dublin, Ireland), expressed as percentage of points seen (average of left and right eye). Mesopic contrast sensitivity and glare sensitivity were both measured, with the Mesotest $\mathrm{II}^{11}$ (Oculus, GmbH, Wezlar, Germany) and the Nyktotest $300^{12}$ (with 502 test disc, Rodenstock, GmbH, Ottobrun, Germany) and expressed as log (percentage contrast). Useful field of view (UFOV) ${ }^{13}{ }^{14}$ was measured with the commercial software (Visual Awareness, Chicago, IL, USA), results expressed as risk category on a 1-5 scale.

All tests were performed binocularly, except visual field. Four subjects had large discrepancies between visual fields of left and right eyes, exclusion of those did not change the results of the analyses.

\section{Ocular disease}

From the clinical notes, medical history, slit lamp examination, non-mydriatic funduscopy and tonometry, it appeared that 22 had subjects had cataract, eight glaucoma, seven diabetes mellitus, two age related macular degeneration, and one (previous) monocular trauma. Thirty five had one or more of these diseases.

\section{Data analysis}

Perceived driving disability (PDD) was obtained by averaging scores of questions $1-5$ (see appendix). PDD at night (PDDN) was calculated by subtracting scores of night-time from daytime driving questions $(\mathrm{PDDN}=$ score $(($ question $2-1)+$ (question $4-3)$ )/2), PDD at unfamiliar places (PDDU) by subtracting scores about driving at unfamiliar places from those about familiar places $(\mathrm{PDDU}=$ score $(($ question $3-1)+$ (question $4-2)$ )/2). spss, version 9.0 for personal computers, was used for statistical analysis.

\section{RESULTS}

Table 1 shows the results of the regression model $(\mathrm{PDD}=\mathrm{b} 0$ + bl $\times$ test results). PDD is most significantly dependent on VA, CS, and UFOV and less, but still significantly on Nyktotest (with and without glare). The Mesotest (with and without glare) is merely close to significance.

Table 1 also shows the results of the similar models for PDDN and PDDU, respectively. Compared to PDD, the slope of PDDN is larger for Nyktotest with glare and Mesotest, with and without glare. The slope is smaller for the remaining tests. Only Nyktotest with glare and Mesotests, with and without glare, are significant. For PDDU, only UFOV is significant.

Subjects with VA $20 / 25$ or better were also selected (Table 1). For PDDN, the slopes for all tests (except visual field) are larger, most markedly for VA, CS, and Nyktotests and 
Table 1 Regression of the perceived driving disability scores on the scores of the various vision screening tests

\begin{tabular}{|c|c|c|c|c|c|c|}
\hline \multirow[b]{2}{*}{ Test } & \multicolumn{3}{|c|}{ All subjects $(n=93)$} & \multicolumn{3}{|c|}{ Subjects with VA $\geqslant 20 / 25(n=72)$} \\
\hline & $\begin{array}{l}\text { Slope of } \\
\text { regression B }\end{array}$ & SE of B & $\mathrm{p}$ Value & $\begin{array}{l}\text { Slope of } \\
\text { regression B }\end{array}$ & SE of B & $\mathrm{p}$ Value \\
\hline \multicolumn{7}{|c|}{ Perceived driving disability PDD } \\
\hline Visual acuity & 56.29 & 10.81 & $<0.001$ & 53.60 & 17.34 & 0.003 \\
\hline Contrast sensitivity & -46.19 & 8.95 & $<0.001$ & -25.11 & 11.14 & 0.027 \\
\hline Visual field & -0.00 & 0.17 & 0.989 & 0.08 & 0.16 & 0.623 \\
\hline Nyktotest without glare & -58.52 & 20.01 & 0.004 & -73.90 & 25.30 & 0.005 \\
\hline Nyktotest with glare & -19.44 & 8.79 & 0.03 & -16.91 & 7.97 & 0.037 \\
\hline Mesotest without glare & -10.07 & 5.09 & 0.051 & -27.24 & 6.62 & $<0.001$ \\
\hline Mesotest with glare & -5.98 & 3.59 & 0.099 & -4.60 & 2.99 & 0.129 \\
\hline UFOV category & 6.35 & 1.51 & $<0.001$ & 3.26 & 1.73 & 0.063 \\
\hline \multicolumn{7}{|c|}{ Perceived driving disability at night and bad weather PDDN } \\
\hline Visual acuity & 10.87 & 13.61 & 0.426 & 38.97 & 27.44 & 0.16 \\
\hline Contrast sensitivity & -6.50 & 11.05 & 0.558 & -34.52 & 16.89 & 0.045 \\
\hline Visual field & -0.00 & 0.19 & 0.832 & 0.03 & 0.24 & 0.912 \\
\hline Nyktotest without glare & -31.48 & 22.44 & 0.164 & -141.48 & 36.68 & $<0.001$ \\
\hline Nyktotest with glare & -21.26 & 9.66 & 0.03 & -37.09 & 11.58 & 0.002 \\
\hline Mesotest without glare & -13.47 & 5.58 & 0.018 & -40.29 & 10.01 & $<0.001$ \\
\hline Mesotest with glare & -8.01 & 3.89 & 0.042 & -10.93 & 4.39 & 0.015 \\
\hline UFOV category & 0.34 & 1.78 & 0.85 & 1.69 & 2.66 & 0.528 \\
\hline \multicolumn{7}{|c|}{ Perceived driving disability at unfamiliar places PDDU } \\
\hline Visual acuity & 9.34 & 6.27 & 0.14 & 26.42 & 12.79 & 0.043 \\
\hline Contrast sensitivity & -8.49 & 5.06 & 0.097 & -8.36 & 8.16 & 0.309 \\
\hline Visual field & -0.00 & 0.09 & 0.984 & 0.09 & 0.11 & 0.412 \\
\hline Nyktotest without glare & -14.64 & 10.42 & 0.164 & -43.93 & 18.36 & 0.019 \\
\hline Nyktotest with glare & -7.61 & 4.54 & 0.097 & -11.39 & 5.70 & 0.05 \\
\hline Mesotest without glare & -3.09 & 2.66 & 0.249 & -8.15 & 5.16 & 0.119 \\
\hline Mesotest with glare & -2.41 & 1.83 & 0.192 & -2.72 & 2.14 & 0.209 \\
\hline UFOV category & 1.85 & 0.80 & 0.024 & 3.36 & 1.20 & 0.007 \\
\hline
\end{tabular}

Table 2 Correlation between perceived driving disability scores and scores of general health, general vision, near vision and distance vision domains

\begin{tabular}{|c|c|c|c|c|c|c|}
\hline & PDDN & PDDU & $\begin{array}{l}\text { General } \\
\text { health GH }\end{array}$ & $\begin{array}{l}\text { General } \\
\text { vision GV }\end{array}$ & $\begin{array}{l}\text { Near vision } \\
\text { NV }\end{array}$ & $\begin{array}{l}\text { Distance } \\
\text { vision DV }\end{array}$ \\
\hline \multicolumn{7}{|l|}{ PDD } \\
\hline Corr coeff & 0.48 & 0.36 & 0.273 & 0.489 & 0.65 & 0.829 \\
\hline p Value & $<0.001$ & $<0.001$ & 0.008 & $<0.001$ & $<0.001$ & $<0.001$ \\
\hline \multicolumn{7}{|l|}{ PDDN } \\
\hline Corr coeff & & 0.272 & 0.173 & 0.065 & 0 & 0.165 \\
\hline p Value & & 0.01 & 0.104 & 0.542 & 0.999 & 0.12 \\
\hline \multicolumn{7}{|l|}{ PDDU } \\
\hline Corr coeff & & & 0.085 & 0.132 & 0.346 & 0.314 \\
\hline p Value & & & 0.424 & 0.213 & 0.001 & 0.003 \\
\hline \multicolumn{7}{|c|}{ General health } \\
\hline Corr coeff & & & & 0.494 & 0.383 & 0.297 \\
\hline p Value & & & & $<0.001$ & $<0.001$ & 0.004 \\
\hline \multicolumn{7}{|l|}{ General vision } \\
\hline Corr coeff & & & & & 0.647 & 0.499 \\
\hline p Value & & & & & $<0.001$ & $<0.001$ \\
\hline \multicolumn{7}{|l|}{ Near vision } \\
\hline Corr coeff & & & & & & 0.849 \\
\hline p Value & & & & & & $<0.001$ \\
\hline
\end{tabular}

Mesotests, with and without glare. For PDDU the slopes of some tests are larger, particularly VA, Nyktotest without glare, and UFOV.

The relation between the effects of VA and each of the remaining tests on PDD was modelled as (PDD $=\mathrm{b} 0+\mathrm{bl} \times$ visual acuity $(\log M A R)+b 2 \times$ test results $)$. In most combinations, the slope for VA was close to that of regression of PDD on VA alone. Only in combination with CS was the slope for VA smaller. The dependency of PDD was significant for CS only.

The PDD score was significantly correlated with PDDN, PDDU and also with GH, GV and, most strongly, with NV and
DV (Table 2). PDDN was correlated with PDDU only. PDDU was correlated, apart from PDDN, with NV and DV.

There was a relation between PPD and the annually driven kilometers $(\mathrm{R}=0.236, \mathrm{~B}=-0.137 \%$ change in score $/ 200 \mathrm{~km})$, but not between PDD, PDDN, or PDDU and driving frequency, dependency, or purpose of driving.

\section{DISCUSSION}

Our study demonstrates that subjects are aware of difficulties due to visual limitations when driving. This counts most 
strongly for visual acuity, but also for other aspects of vision, such as contrast sensitivity, glare sensitivity, and UFOV.

We found that Nyktotests and Mesotests specifically relate to disability at night and bad weather conditions. Disability glare is condition dependent. This may explain the weakness of the relation with PDD. In addition, this may explain the absence of correlation between PDDN and the GV, NV, and DV questions. The relation between PDDN and Nyktotests and Mesotests supports the usefulness of Nyktotests and Mesotests under these specific conditions, particularly so in subjects with "good" visual acuity. However, these tests are no generalised methods for measuring mesopic contrast sensitivity and disability glare. Measurement conditions provide a simulation of night-time driving only. ${ }^{11}$ The Nyktotests and Mesotest differ from each other in background illumination levels $\left(0.1 \mathrm{~cd} / \mathrm{m}^{2}\right.$ and $0.0316 \mathrm{~cd} / \mathrm{m}^{2}$ for Nyktotests and Mesotest, respectively). This may explain the more close relation between Nyktotest with PDD and between Mesotest and PDDN. Probably, the applicability of the tests is limited owing to high failure rates; in our results around $40 \%$ for each test with glare and $9 \%$ and $13 \%$ for Nykotest and Mesotest without glare, respectively.

The UFOV test assesses speed of visual processing, ability to divide attention and ability to pay selective attention to a presented target. ${ }^{13}$ This is brain function rather than ocular function. We assumed that this test could be a model for specific difficulties with driving in unfamiliar places. The specific relation of PDDU with UFOV, especially in subjects with "good" visual acuity, demonstrates the fairness of this assumption and also the capacity of UFOV to predict perceived disabilities under such conditions.

The additional value of contrast senstivity measurements above measurement of visual acuity has been debated. ${ }^{15}$ Our results confirm that the effects are at least partly independent and that even in subjects with "good" visual acuity, measurement of contrast sensitivity reveals additional information.

\section{A questionnaire for assessment of vision disability}

Most widely used (and evaluated) is the NEI-VFQ25 questionnaire. ${ }^{1}$ Its results related well to the severity of several ocular diseases..$^{2-5}$ The NEI-VFQ measures vision related quality of life and not task dependent vision disability. Therefore, application in our experiments would have been inappropriate. Still, the excellent correlation between PDD and NV and DV demonstrates the validity of the PDD parameter. In contrast, the absence of correlation between PDDN and NV or DV demonstrates the incapacity of NV and DV to show night driving disabilities. An essential property of PDDU and PDDN is subtraction of scores (for example, subtraction of daytime and night-time driving scores) in order to reveal condition dependent disability and to reduce the role of interindividual variability. Such subtraction, in our study, has proved to be very useful in relating condition specific disabilities to condition specific tests.

\section{ACKNOWLEDGEMENTS}

This study was performed with a grant of the European Commission. We thank Carl Zeiss BV, Rodenstock GmbH and Oculus $\mathrm{GmbH}$ for the provision of Nyktotests and Mesotests. The authors have no proprietary interest in any of the equipment used in this study.

\section{APPENDIX}

The core of the questionnaire

1 How much difficulty do you have driving during daytime in familiar places?

2 How much difficulty do you have driving during bad weather conditions (rain/snow) and during night-time in familiar places?

3 How much difficulty do you have driving during daytime in unfamiliar places?

4 How much difficulty do you have driving during bad weather conditions (rain/snow) and during night-time in unfamiliar places?

5 How much difficulty do you have driving during heavy traffic, such as in rush hour and in city centres?

\section{(POSSIBLE ALTERNATIVES: NO DIFFICULTY AT ALL/LITTLE DIFFICULTY/MODERATE DIFFICULTY/EXTREME DIFFICULTY/STOPPED DOING THIS BECAUSE OF EYESIGHT/STOPPED BECAUSE OF OTHER REASONS)}

\section{Authors' affiliations}

L J van Rijn, R Kaper, H J Völker-Dieben, Department of Ophthalmology, Vrije Universiteit Medical Centre, Amsterdam, Netherlands

H Wilhelm, S Heine, Universitäts-Augenklinik, Tübingen, Germany M Emesz, S Nitsch, G Grabner, Landesaugenklinik für Augenheilkunde und Optometrie, Salzburg, Austria

Correspondence to: Dr L J van Rijn, Vrije Universiteit Medical Centre, PO Box 7057, NL-1007 MB, Amsterdam, Netherlands; vanrijn@vumc.nl

Accepted for publication 11 June 2002

\section{REFERENCES}

1 Mangione CM, Berry S, Spritzer K, et al. Identifying the content area for the 51 -item National Eye Institute Visual Function Questionnaire:results from focus groups with visually impaired persons. Arch Ophthalmol 1998; 1 16:227-33.

2 Parrish RK 2nd, Gedde SJ, Scott, IU, et al. Visual function and quality of life among patients with glaucoma. Arch Ophthalmol 1997;115:144755.

3 Gutierrez $\mathbf{P}$, Wilson MR, Johnson $\mathbf{C}$, et al. Influence of glaucomatous visual field loss on health-related quality of life. Arch Ophthalmol 1997; 115:777-84.

4 Cole SR, Beck RW, Moke PS, et al. The National Eye Institute Visual Function Questionnaire: experience of the ONTT. Optic Neuritis Treatment Trial. Invest Ophthalmol Vis Sci 2000;41:1017-21.

5 Klein R, Moss SE, Klein BE, et al. The NEI-VFQ-25 in people with long-term type 1 diabetes mellitus: the Wisconsin Epidemiologic Study of Diabetic Retinopathy. Arch Ophthalmol 2001;119:733-40.

6 Ferris FL, Kassoff A, Bresnick GH, et al. New visual acuity charts for clinical research. Am J Ophthalmol 1982;94:91-6.

7 Arditi, A, Cagenello R. On the statistical reliability of letter-chart visual acuity measurements. Invest Ophthalmol Vis Sci 1993;34:120-9.

8 Pelli DG, Robson JG, Wilkins AJ. The design of a new letter chart for measuring contrast sensitivity. Clin. Vis Sci 1988;2:187-99.

9 Rubin GS. Reliability and sensitivity of clinical contrast sensitivity tests. Clin Vis Sci 1988;2:169-77.

10 Elliot DB, Sanderson K, Conkey, A. The reliability of the Pelli-Robson contrast sensitivity chart. Ophthalmic Physiol Opt 1990;10:21-4.

11 Aulhorn E, Harms, H. Über die Untersuchung der Nachtfahreignung von Kraftfahrern mit dem Mesoptometer. Klin Monatsbl Augenheilkd 1970;157:843-73.

12 Hartmann, E, Wehmeyer K. Untersuchung des Dämmerungssehens und des Blendempfindens met dem neven Nyktometer. Klin Monatsbl Augenheilkd 1980;176:859-63

13 Ball K, Owsley C. The useful field of view test:a new technique for evaluating age-related declines in visual function. J Am Optom Assoc 1993;64:71-9.

14 Owsley C. Vision and driving in the elderly. Optom Vis Sci 1994;71:727-35.

15 Brown B, Lovie-Kitchin JE. High and low contrast acuity and clinical contrast sensitivity tested in a normal population. Optom Vis Sci 1989;66:467-73. 